\title{
O Impacto da Religião no Crescimento Econômico: Uma Análise Empírica para o Brasil em 1991, 2000 e 2010
}

\author{
Luan Vinícius Bernardelli
}

Ednaldo Michellon ${ }^{2}$

\begin{abstract}
Resumo
Uma questão intrigante aos economistas é explicar o motivo de algumas nações crescerem mais do que outras. Além dos modelos de crescimento tradicionais, que consideram trabalho, capital fixo e humano, existem formulações complementares que incluem fatores culturais para analisar essa relação, sendo a religião uma das variáveis que mais influencia os indivíduos, pois oferece uma forma de conduta de vida e hábitos diários praticados pelos fiéis. No Brasil, são perceptíveis as transformações ocorridas no campo religioso, em que, de 1980 a 2010, a proporção da população cristã-protestante cresceu 15,55 pontos percentuais, enquanto a proporção da população católica declinou aproximadamente 24,10 . Assim, este trabalho objetivou verificar se uma proporção maior de protestantes tradicionais e pentecostais possui relação positiva com a renda per capita dos municípios brasileiros, além de testar empiricamente a importância das variáveis capital fixo e capital humano. Para esta finalidade, utilizou-se a regressão em dados em painel, com base nos microdados dos Censos Demográficos. Os resultados obtidos mostram que a expansão do protestantismo tradicional e pentecostal contribuiu positivamente para aumentar o nível de renda do país. Desse modo, o trabalho trouxe luz à importância da economia da religião em questões relacionadas ao crescimento econômico.
\end{abstract}

\section{Palavras-Chave}

Crescimento. Comportamento. Natureza Humana. Capitalismo. Brasil.

\begin{abstract}
An intriguing question to economists is to explain why some nations grow more than others. In addition to the traditional growth models, which consider labor, fixed capital, and human capital, there are complementary formulations that include cultural factors to analyze this relationship, with religion being one of the variables that most influence individuals since it offers

1 Doutorando em Economia - Universidade Estadual de Maringá (UEM)

Endereço: Av. Colombo, 5790, Bloco C 34 - Sala 5 - Maringá /PR - Brasil - CEP: 88040-900

E-mail: luanviniciusbernardelli@gmail.com - https://orcid.org/0000-0003-1410-2318

2 Professor - Universidade Estadual de Maringá (UEM)

Endereço: Av. Colombo, 5790, Bloco J 45 - Sala 107 - Maringá /PR - Brasil

CEP: 88040-900 - E-mail: emichellon@uem.br - https://orcid.org/0000-0003-3376-9003

Recebido: 06/03/2017. Aceite: 27/12/2017.
\end{abstract}


a way of life conduct and daily habits practiced by the faithful. In Brazil, the transformations occurring in the religious field, from 1980 to 2010, where the proportion of the Protestant Christian population increased by 15.55 percentage points, while the proportion of the Catholic population declined by approximately 24.10. Thus, this study aimed to verify if a higher proportion of Traditional and Pentecostal Protestants has a positive relationship with the per capita income of the Brazilian municipalities, besides empirically testing the importance of the variables fixed capital and human capital. For this purpose, the panel regression was used, based on the Demographic Census microdata. The results show that the expansion of traditional and Pentecostal Protestantism contributed positively to increasing the country's income level. In this way, the work brought light to the importance of the economy of religion in issues related to economic growth.

\section{Keywords}

Growth. Behavior. Human nature. Capitalism. Brazil.

\section{JEL Classification}

Z12. O40. 043 .

\section{Introdução}

Uma questão fundamental nos estudos sobre crescimento econômico é explicar por que alguns países são mais ricos do que outros. De acordo com o World Bank (2018), em 2016, o Produto Interno Bruto(PIB) em paridade de poder de compra (PPC), per capita, dos Estados Unidos equivalia a 4,79 vezes ao da África do Sul, 3,79 vezes ao do Brasil e 1,87 vezes ao de Portugal; desde então, diversos autores buscam explicar os determinantes do crescimento econômico.

Uma das principais contribuições para essa temática ocorreu a partir do trabalho seminal de Solow (1956), ${ }^{1}$ fundamentado sobre a importância do capital fixo. Posteriormente, alguns autores como Schultz (1961) e Becker (1962) passaram a destacar a importância do fator de produção capital humano. Além dos modelos de crescimento tradicionais, resultados empíricos de Huntington (1996), Landes (1998) e o de Inglehart e Baker (2000) indicam que análises sobre o crescimento econômico deveriam considerar fatores culturais, pois certamente possuem relação com o crescimento econômico e tratam características como honestidade, parcimônia e vontade de trabalhar.

${ }^{1}$ Para uma apresentação mais completa ver Solow (1956). 
Ao se relacionar questões culturais, Huntington (1996) fundamenta que um agrupamento cultural pode ser definido por elementos como a linguagem, a história, a religião, os costumes, as instituições e pela autoidentificação subjetiva das pessoas.

Especificamente no contexto religioso, evidências mostram uma influência direta sobre o modo de vida das pessoas e sobre o processo de desenvolvimento dos países desde os primórdios de sua existência, e um dos primeiros a reconhecer essa relação foi Smith (2007), Laveleye (1985) e, mais à frente, Weber (2013). ${ }^{2}$

A Economia da Religião, embora tenha sido fundamentada nos trabalhos supracitados, tornou-se um campo científico somente quando as técnicas estatísticas possibilitaram testar as hipóteses estabelecida por esses autores, o que ocorreu após a Segunda Guerra Mundial, e foram, posteriormente, aplicadas em estudos sociais (McCleary 2011). A importância atribuída neste estudo empírico ao Brasil decorre da significativa alteração no campo religioso visualizado nos últimos anos, em que a proporção de protestantes cresceu 15,55 pontos percentuais, sendo 3,06\% dos protestantes tradicionais e 12,49 pontos percentuais dos protestantes pentecostais. Já em relação à proporção de católicos, declinou 24,10 pontos percentuais.

Com base nos arcabouços teóricos sobre a importância da religião para os aspectos culturais e econômicos, sugeridos por Smith (2010), Laveleye (1985) e Weber (2013), Huntington (1996), Landes (1998), Inglehart e Baker (2000), McCleary (2011), juntamente com a alteração presenciada no Brasil, questiona-se: (i) qual é o impacto da alteração do campo religioso brasileiro sobre o crescimento econômico do país?

À luz dessa contextualização e da problemática estabelecida, este trabalho propôs analisar a influência da religião sobre o crescimento econômico, com base no nível de renda per capita da população dos municípios do Brasil. A hipótese estabelecida aponta que a ética protestante é, de modo geral, um fator que contribui positivamente para o crescimento econômico (Weber 2013). ${ }^{3}$ Além disso, que o avanço pentecostal tem o potencial de

2 As obras de Smith, Laveleye e Weber foram publicadas, respectivamente, em 1776, 1875 e 1904, e se destacaram por serem pioneiras em relacionar aspectos sobre a Economia da Religião.

3 Essa relação pode se afugentar da ideia inicial de Weber (2013), e se relacionar à teoria de Becker e Woessmann (2009), de que as economias protestantes prosperam porque a instrução da leitura da Bíblia gera capital humano crucial para a prosperidade econômica, contudo, este trabalho não contemplará esta distinção. 
transformar a moral individual, a cultura, a política e a economia, contribuindo para a elevação de renda dos indivíduos (Martin 1990).

O método estatístico aplicado para testar esta hipótese foi a técnica de dados em painel, formulado para os anos de 1991, 2000 e 2010. Os dados sobre os aspectos religiosos, capital humano e crescimento populacional foram extraídos dos Censos Demográficos, e a proxy para capital fixo do Instituto de Pesquisa Econômica Aplicada - IPEA (2018).

Para atender a estes objetivos, o presente estudo está dividido em seis partes, incluindo esta introdução; a segunda traz alguns conceitos sobre o crescimento econômico e o relaciona com os aspectos religiosos; a terceira apresenta alguns resultados empíricos sobre a relação entre a economia e religião; a quarta retrata os procedimentos metodológicos aplicados na análise empírica; a quinta expõe os resultados obtidos, bem como promove a interligação entre o levantamento teórico e empírico e, por fim, a sexta apresenta as considerações finais.

\section{O Crescimento Econômico e o Modelo de Mankiw, Romer e Weil (1992)}

Ao longo dos últimos séculos, os padrões de vida no mundo alcançaram níveis inimagináveis para os antepassados, ainda que as comparações sejam difíceis, a melhor evidência disponível sugere que o salário atual médio real nos Estados Unidos e na Europa Ocidental é entre 10 e 30 vezes maior do que há um século, e entre 50 e 300 vezes maior do que há dois séculos (Romer 2012).

Devido à importância do crescimento econômico, muitos pesquisadores elegem possíveis variáveis explicativas para determiná-lo. Embora o modelo de Solow (1956) não seja o primeiro estudo sobre o crescimento econômico, é o ponto de partida de quase todas as análises. A principal conclusão do modelo é que o capital fixo não é suficiente para explicar a renda per capita, por conseguinte, relaciona que existem também outras variáveis como, por exemplo, a tecnologia (Romer 2012). ${ }^{4}$

4 Ver mais sobre Solow (1956). 
Segundo Solow (1956), o produto " $Y$ " pode ser determinado através de uma função de produção que contemple o progresso tecnológico " $A$ ", o capital " $K$ " e o trabalho " $L$ ". Dessa forma, por meio de uma função CobbDouglas com retornos constantes de escala, tem-se que:

$$
Y(t)=K(t)^{\alpha}[A(t) L(t)]^{1-\alpha}, 0<\alpha<1
$$

Em que: " $\alpha$ " $\mathrm{e}$ " $(1-\alpha)$ " representam as elasticidades do produto em referência à " $K$ " e " $L$ ", respectivamente. As unidades de trabalho, $A(t) L(t)$, crescem à taxa $(n+g)$. Solow (1956) considera taxa de poupança e crescimento populacional como variáveis exógenas e destaca que são fatores fundamentais para definir o nível de renda per capita de um país.

Resumidamente, fornece embasamentos de que quanto maior a taxa de poupança, mais rico o país é, e quanto maior a taxa de crescimento populacional, mais pobre o país é. Assim, a razão capital-trabalho no estado estacionário tem relação positiva com a taxa de poupança ${ }^{5}$ e negativa com o crescimento populacional " $(n)$ ".

Desse modo, admitindo que os fatores são remunerados de acordo com seu produto marginal, pode-se estimar os coeficientes pertencentes à poupança e à depreciação efetiva do capital " $\delta$ ". Por conseguinte, a renda per capita no estado estacionário é determinada como:

$$
\ln \left[\frac{Y(t)}{L(t)}\right]=\ln A(0)+g_{t}+\frac{\alpha}{1-\alpha} \ln \left(s_{k}\right)-\frac{\alpha}{1-\alpha} \ln (n+g+\delta)
$$

A poupança é gerada de forma exógena e investida " $\left(s_{k}\right)$ " e o restante é consumido. O capital se deprecia a uma taxa constante " $\delta$ "; a taxa de crescimento população é representado por " $n$ " e a tecnologia a uma taxa constante e exógena " $g$ ".

As previsões do modelo de Solow (1956) fornecem embasamentos consistentes sobre os determinantes do nível de renda per capita. Entretanto, nas palavras de Mankiw, Romer e Weil (1992), trata-se de uma formulação muito simples para compreender essa complexa relação. Para uma maior precisão, esses autores enfatizam a importância do investimento em capital humano e sugerem que existe uma correlação com o capital fixo.

\footnotetext{
${ }^{5}$ A poupança no modelo de Solow $S_{k}$ é considerado como investimento $K$.
} 
Em outras palavras, um maior estoque de capital humano potencializa os rendimentos do estoque de capital físico.

De acordo com Schultz (1961), conquanto seja óbvio que as pessoas acumulem habilidades e conhecimentos úteis, não é óbvio que essas habilidades e conhecimentos sejam uma forma de capital. Para Schultz (1961), gastos diretos com educação, saúde e migração interna para aproveitar as melhores oportunidades de emprego são exemplos claros de investimento em capital humano.

Desse modo, Mankiw, Romer e Weil (1992) fundamentam que a omissão do capital humano poderia gerar estimadores tendenciosos, uma vez que essa variável está correlacionada à taxa de poupança e ao crescimento populacional. Assim, estenderam o modelo de Solow incluindo o capital humano " $H$ " na análise. A Equação (3) apresenta a relação proposta por esses autores.

$$
Y(t)=K(t)^{\alpha} H(t)^{\beta}[A(t) L(t)]^{1-\alpha-\beta}
$$

Em que " $\alpha$ " e " $\beta$ " representam as elasticidades do produto em relação aos insumos. Formalmente, tem-se:

$$
\begin{gathered}
\ln \left[\frac{Y(t)}{L(t)}\right]= \\
\quad \ln A(0)+g_{t}-\frac{\alpha+\beta}{1-\alpha-\beta} \ln (n+g+\delta)+ \\
\frac{\alpha}{1-\alpha-\beta} \ln \left(s_{k}\right)+\frac{\beta}{1-\alpha-\beta} \ln \left(S_{h}\right)
\end{gathered}
$$

Em que, " $S_{h}$ "representa a fração de renda investida em capital humano. Com base nessa equação, observa-se que a renda, no estado estacionário, está diretamente relacionada com o capital físico e humano e inversamente à taxa de crescimento populacional. Com a finalidade de operacionalizar a Equação (4), o modelo pode ser apresentado pela Equação (5):

$\ln \left[\frac{Y(t)}{L(t)}\right]=\beta_{0}+\beta_{1} \ln S_{k}+\beta_{2}(n+g+\delta)+\beta_{3} \ln S_{h}+\mu_{i t}$

Por meio da Equação (5), é possível analisar os pressupostos sugeridos por Mankiw, Romer e Weil (1992). Contudo, assim como fundamentado anteriormente, existem outros fatores que corroboram para que algumas nações cresçam mais que outras. 
De acordo com Olson (1996), formulações complementares enfatizam que outras variáveis devem ser inclusas, tais como as atitudes culturais em relação ao trabalho, economia e empreendedorismo.

Firmado nos indicativos da alta relação entre fatores culturais e religiosos, prestados por Smith (2007), Weber (2013), Huntington (1996), Landes (1998), Barro e McCleary (2003), McCleary (2011), entre outros, a próxima seção apresenta algumas considerações sobre as religiões dominantes no Brasil e promove a interligação com o modelo de crescimento apresentado.

\subsection{A Religião e sua Relevância para o Crescimento Econômico}

De forma geral, o cristianismo é a religião que mais fortemente caracteriza a sociedade ocidental e, há 2 mil anos, permeia a história, a literatura e a filosofia. Assim, conhecer o cristianismo é pré-requisito para compreender a sociedade e a cultura ocidental (Gaarder, Hellern e Notaker 2005).

Para Ekelund Junior, Hébert e Tollison (2002), a maioria dos historiadores da igreja medieval concorda que a venda de indulgências pela Igreja Católica desempenhou um papel proeminente ao incentivar a entrada competitiva por religiões concorrentes. Como uma espécie de guardião do céu, a Igreja Católica envolvia-se em atividades aparentemente semelhantes às que ocorrem em um sistema de justiça criminal.

A indulgência está relacionada ao Sacramento da Penitência. Na Penitência, esperavam-se o arrependimento do pecador, a confissão na presença de um sacerdote, a absolvição e a satisfação imposta. Era opinião corrente que o pecado não só acarretava culpa, mas também castigo. Esse castigo deveria ser assumido na terra ou expiado no purgatório. Embora as indulgências fossem amplamente aplicadas pela Igreja Católica, os teólogos possuíam opiniões distintas sobre essas práticas, não havendo a necessária clareza acerca do assunto (Lutero 2004).

A prática da cobrança de indulgências pela igreja católica permeou o mundo durante muito tempo e causou uma grande transferência de renda de pequenas cidades para Roma, gerando uma clara concentração de riquezas. Para Ekelund Junior, Hébert e Tollison (2002), os principais motivos do sucesso de Martinho Lutero foram os abusos realizados pela Igreja Católica, 
envolvendo indulgências e as tentativas de extrair rendas associadas às inovações doutrinárias. Portanto, a Reforma Protestante surgiu a partir do descontentamento de grande parte da população com a Igreja Católica entre os anos de 1517 e 1564 . As críticas eram sobre as questões religiosas, políticas e socioeconômicas. As indulgências tinham destacada importância sob o aspecto financeiro e muitos projetos da Igreja eram financiados com essas práticas. Para os fiéis, a indulgência era uma oportunidade de se protegerem do purgatório e do juízo eterno (Lutero 2004).

Em outras palavras, "a salvação passou a ser comprada por dinheiro, todos tinham o direito de ir para o céu, desde que pagassem o pedágio, em forma de indulgência, exigido pelo "Vaticano" " (Michellon 2006: 25). Contudo, em 1517, Martinho Lutero pregou suas noventa e cinco teses à porta da igreja em Wittenberg, e deu o primeiro golpe para a disseminação do cristianismo protestante, que surgiu como um sistema de adoração e crença organizadas em um grande evento religioso (Landes 1998). A afixação das 95 Teses, que se deu em 31 de outubro de 1517, é comemorada anualmente como Dia da Reforma Protestante, embora a intenção não fosse deflagrar um movimento, pois Lutero objetivava promover esclarecimentos teológicos acerca de questões importantes e de práticas promovidas pela Igreja Católica (Lutero 2004).

Com isso, foram visíveis as alterações ocorridas no meio econômico. Após a reforma, em vários países, a renda que antigamente pertencia à Igreja Católica Romana constituiu-se em um fundo suficiente, não apenas para pagar os salários competentes aos sacerdotes protestantes, mas também para custear, com pouca ou nenhuma adição, todas as outras despesas do Estado (Smith 2007).

Landes (1998) pontua que o protestantismo auxiliou na ascensão do capitalismo industrial, não por meio de uma maior liberdade religiosa, mas definindo e sancionando uma ética do comportamento cotidiano que conduziu ao sucesso empresarial, assim como sugerido por Weber (2013), dando origem a toda forma de refutação. Os católicos romanos não sabiam se deveriam aceitá-la como elogio ou denunciá-la como crítica, no entanto, muitos historiadores rejeitaram a ideia de que a religião poderia motivar e moldar o modo de produção.

6 O termo "Vaticano" está entre aspas porque este só passa a representar a sede da Igreja Católica a partir de 1929, com o Tratado de Latrão, firmado entre o papa e Benito Mussolini, tratado este que põe fim à chamada "Questão Romana", que existia desde a unificação da Itália (1860/70) (Michellon 2006: 25). 
Laveleye (1985) é mais enfático ao tratar essa questão; para ele, é perceptível que a ética protestante favorece o desenvolvimento das nações. Um dos fatores que explica essa relação é a ênfase ao nível de instrução prestado pelos protestantes. Esse processo também pode ser um reflexo da forma de condução do culto protestante, que tem por base a Bíblia e fomenta o hábito da leitura. Por outro lado, o culto católico é fundamentado nos sacramentos e em práticas tais como a confissão, a missa, o sermão; práticas que não exigem leitura. Saber ler, portanto, não é necessário e foi por muito tempo considerado como um caminho que conduz à heresia (Laveleye 1985).

Os resultados da reforma protestante apareceram por meio da elevação do nível de alfabetização e do número de candidatos para a educação avançada, assim como da continuidade da alfabetização entre as gerações, pois as mães também deveriam ser alfabetizadas. Desse modo, de acordo com McCleary (2011), os protestantes foram motivados a se tornar alfabetizados porque a salvação não viria pela intercessão de um sacerdote, mas através da compreensão da palavra escrita por Deus na Bíblia. Além disso, a cultura protestante foi disseminada em diversos países, uma vez que os missionários protestantes promoveram a divulgação em massa de materiais escritos para fins de proselitismo e conversão, as impressões foram introduzidas em vários países, publicando materiais religiosos e comerciais, como jornais em línguas indígenas (Woodberry 2011).

Desse modo, o protestantismo ofereceu caminhos alternativos e menos dispendiosos para a salvação, porque o crente era salvo pela fé, interpretada como um dom de Deus, e a salvação pessoal não veio da igreja institucional, mas diretamente da graça de Deus. Além disso, em sua forma inicial, o protestantismo tinha menos mecanismos pelos quais seus agentes poderiam extrair recursos financeiros e "vendia" a redenção muito mais barata, mesmo admitindo a alocação aparentemente aleatória da graça de Deus (Ekelund Junior, Hébert e Tollison 2002).

À luz desse conceito, Weber (2013), teorizou a ética protestante com base na história econômica. Sua fundamentação foi centrada através dos processos históricos das grandes civilizações do mundo. Segundo McCleary (2011), Weber não tinha habilidades linguísticas e possuía acesso a fontes primárias de materiais, contudo, sua contribuição foi quebrar a barreira intelectual de ver a religião dentro de certos parâmetros conceituais. 
Uma das ponderações realizadas por Weber (2013) foi sobre as distintas características pessoais existentes entre os católicos e os protestantes. O católico é mais tranquilo, tem menos impulso aquisitivo em relação ao protestante, prefere uma vida mais segura a uma vida excitante e cheia de riscos, mesmo que esta possa lhe propiciar a oportunidade de ganhar honrarias e riquezas. Já na visão protestante, Deus se encontra operando em todas as circunstâncias da vida, logo, isso indica que se ocorrer uma oportunidade de lucro, um cristão de fé deve seguir esse chamado e aproveitá-la.

De forma a complementar a obra de Weber (2013), outros autores realizam contribuições importantes acerca das novas derivações do protestantismo, ocorridas a partir de 1910. De acordo com Marcantonio Junior (2016), diversos países enfrentaram alterações no campo religioso nos últimos anos, tendo como predominância o crescimento das denominações pentecostais.

Atualmente, a influência e o tamanho da comunidade pentecostal no Brasil são notáveis, a transição religiosa acelerou no país após uma série de transformações estruturais, como a urbanização, industrialização, ampliação e diversificação do padrão de consumo, integração de transportes e telecomunicações, ampliação das políticas de proteção social (Alves; Cavenaghi; Barros 2014). Segundo Anuatti-Neto e Narita (2004), qualquer estudo sobre religiões, no Brasil, deve ter como referência o crescimento explosivo das novas instituições pentecostais durante os anos 1980.

Conforme fundamenta Martin (1990), a expansão pentecostal beneficiouse da ruptura da união entre Igreja e Estado, da quebra do monopólio religioso do catolicismo, da fraqueza institucional da Igreja Católica e da permanência de uma cultura não secularizada, intensamente religiosa. Martin (1990) ainda complementa que a América Latina estaria passando por uma "reforma protestante", cujas implicações sociais, econômicas e políticas seriam semelhantes às ocorridas na Europa do século XVI.

O movimento pentecostal brasileiro teve três grandes ondas de crescimento. Iniciando a primeira onda em 1910, quando a Congregação Cristã e a Assembleia de Deus chegaram. A segunda onda ocorreu na década de 1950 e início dos anos 1960, com a fragmentação do campo pentecostal, formando três grandes grupos: A Igreja Quadrangular, Igreja Brasil para Cristo e Deus é Amor. A terceira onda começou no final da década de 1970 e ganhou força nos anos 80. Seus principais representantes são a 
Igreja Universal do Reino de Deus e a Igreja Internacional da Graça de Deus (Freston 2001).

Martin (1990) defende a ideia de que o avanço pentecostal tem o potencial de transformar a moral individual, a cultura, a política e a economia dos países latino-americanos. Algumas justificativas para esse argumento são encontradas na literatura. De acordo com Stoll (1990), as igrejas pentecostais incentivam a responsabilidade individual, promovem padrões éticos universais, reestruturam relações familiares e de gênero, ajudam os pobres a reorganizar a vida. Para Almeida (2004), as igrejas pentecostais desempenham um papel importante na formação de redes comunitárias de solidariedade e sociabilidade e na atenuação da vulnerabilidade social.

Martin (1990) pontua que o protestantismo pentecostal desenvolve e aprimora as habilidades de liderança, comunicação, expressão, oratória, organização, voluntarismo, pontualidade, honestidade, parcimônia, rejeição ao álcool, respeito às mulheres, ética no trabalho, instituições educacional e de lazer, além do sentido de valor pessoal. Assim, Mariano (2011) conclui que o pentecostalismo constitui um dos fenômenos religiosos mais estudados no Brasil nas últimas décadas. Considerando sua crescente relevância como movimento religioso, como força demográfica, como legislador e como empreendedor midiático no país.

Dessa forma, fica evidente que, além das questões pontuadas pelos modelos de crescimento supracitados, a dinâmica econômica de um país ocorre por meio de seus agentes, isto é, o comportamento da população em relação ao consumo, poupança, produtividade, educação, enfim, às decisões diárias. Assim, por meio dessas fundamentações e com o objetivo de representar os aspectos culturais contidos no comportamento protestante teorizado na literatura, o modelo de Mankiw, Romer e Weil (1992) pode ser ampliado da seguinte forma:

$$
\begin{array}{r}
\ln \left[\frac{Y(t)}{L(t)}\right]=\beta_{0}+\beta_{1} \ln S_{k}+\beta_{2}(n+g+\delta) \\
\beta_{3} \ln S_{h}+\beta_{4} \ln P_{-} P+\beta_{5} \ln P_{-} T+\mu_{i t}
\end{array}
$$

Em que "P T" representa a proporção da população protestante tradicional e "P_P" representa a proporção da população protestante pentecostal.

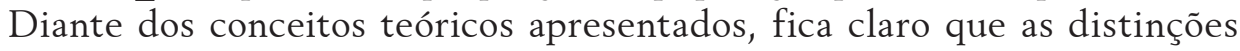


entre o catolicismo e o protestantismo tradicional e pentecostal podem modificar a relação do indivíduo com os fatores econômicos e, como consequência, alterar a dinâmica econômica de toda a sociedade. ${ }^{7}$ Assim, com a finalidade de expor os conceitos práticos dessa teoria, a próxima seção apresenta os resultados de alguns estudos empíricos acerca dessa temática.

\section{Estudos Empíricos}

Com base nas seções anteriores, verifica-se que diversos autores buscam evidenciar as alterações culturais e econômicas advindas dos aspectos religiosos. Um dos primeiros a relacionar aspectos econômicos e religiosos foi Smith (2010), o qual atribuiu que uma das mais importantes contribuições da religião ao processo de desenvolvimento é seu funcionamento como um mecanismo de conduta moral. Para Smith (2010), em sociedades nas quais a crença em Deus era disseminada, a ideia de estar sempre agindo aos olhos de um ser superior, é um motivo capaz de restringir as ações humanas. É assim que a religião reforça o sentido natural do dever, é a razão pela qual a humanidade geralmente está disposta a confiar na honestidade daqueles que parecem profundamente impressionados com os sentimentos religiosos (Smith 2010).

Já para Weber (2013), as práticas e as crenças religiosas tiveram consequências econômicas importantes no processo de desenvolvimento dos países, pois a compreensão de que a salvação seria realizada por obras ligadas à produtividade, incentivava o trabalho e aumentava o nível de mão de obra disponível. Weber teorizou a ética protestante à luz da história econômica e sua fundamentação é centrada nos processos históricos das grandes civilizações do mundo (Keyes 2002).

Motivado por esses pressupostos, Lenski (1961) testou empiricamente a tese de Weber. Por meio de um banco de dados coletado em Detroit, o trabalho desse autor constatou uma forte relação entre a religião e os aspectos culturais, impactando diversas variáveis macroeconômicas. O autor dividiu em quatro grupos de religião e raça; protestantes brancos, protestantes negros, católicos e judeus e obteve diversas descobertas, como a de que a di-

7 Também será incluído uma segunda especificação que unifica os protestantes, representando os Protestantes totais. 
ferença entre a riqueza dos protestantes e dos católicos estava aumentando, diferentemente das hipóteses anteriormente existentes, que estabeleciam que haveria uma convergência de renda entre essas duas religiões.

Contrariamente aos estudos de Lenski (1961), Stark e Glock (1968) desenvolveram um modelo que classificou os EUA em cinco distintas religiões e os resultados indicaram que a religião não exercia influência nos hábitos e nas atividades econômicas, limitando o campo dos estudos da Economia da Religião. Eles ainda apontaram que a secularização da crença, associada ao declínio na participação das atividades religiosas, levaria ao fim das igrejas cristãs. Em poucas palavras, indicaram que, no futuro, não existirá nenhuma razão efetiva para a igreja existir, pois em nada afetaria o comportamento humano.

No entanto, Stark e Glock (1968) estavam errados, pois não consideraram questões relacionadas aos aspectos culturais, influenciados pela crença religiosa. O autor, então, prestou retratação em um trabalho posterior e segundo Stark (1984), em novas análises foi possível mostrar empiricamente que a religião afeta a sociedade, não através da produção de culpa ou medo do fogo do inferno, mas que ela possui uma força para moldar o indivíduo por meio de aspectos comunitários.

Entretanto, há outros indicativos sobre o impacto religioso nos níveis de renda. O estudo de Azzi e Ehrenberg (1975) constatou que o custo de oportunidade do tempo influencia escolhas religiosas nos EUA. Como por exemplo, as mulheres, cujos salários são normalmente mais baixos, tendem a destinar mais tempo em atividades religiosas. Já indivíduos que auferem aumentos reais nos salários, tendem a dedicar menos tempo à igreja, indicando uma relação negativa entre religião e renda.

Em um posicionamento contrário às fundamentações prestadas por Azzi e Ehrenberg (1975), Sacerdote e Glaeser (2001) pontuam que as pessoas mais instruídas têm um incentivo maior para participar de atividades em grupo, incluindo os serviços da igreja, o que indica a existência de uma relação positiva entre educação e as crenças religiosas.

Ao verificar questões ligadas à Reforma Protestante, Michellon, Santos e Suzuki (2012) constataram a veracidade da hipótese de que os povos e nações influenciados pela Reforma Protestante, ou que adotaram o protestantismo como base religiosa, são hoje os mais desenvolvidos do mundo. 
Já derivação pentecostal do movimento protestante diferencia-se por distintas formas do protestantismo tradicional. Para o Pew Research Center (2006) os indivíduos das denominações pentecostais são os que mais frequentemente alegam praticar os "dons do Espírito Santo", como fazer milagres e curar pessoas. Os protestantes pentecostais leem a Bíblia mais literalmente e compartilham sua fé com os não cristãos com mais frequência, tendo como característica comum receber revelações de Deus, testemunhar exorcismos e disseminar o evangelho (Pew Research Center 2006).

Assim, fica evidente que os impactos da transição no cenário religioso, fundamentado pelos dados dos Censos Demográficos, está associada com novos hábitos de vida, retratando impactos diretos nos níveis de renda, caracterizando-se como uma temática que deve ser investigada por meio de uma modelo de crescimento econômico.

\section{Procedimentos Metodológicos}

O método estatístico aplicado ao presente estudo foi a técnica de dados em painel, que é uma ferramenta que aborda uma combinação entre séries temporais e dados de corte transversal. De acordo com Greene (2012), conjuntos de dados que combinam séries temporais e cortes transversais são comuns na economia e isso ocorre porque a análise de dados em painel permite que o pesquisador aprenda sobre os processos econômicos enquanto contabiliza a heterogeneidade dos indivíduos.

Cameron e Trivedi (2005) fundamentam que os dados do painel são observações repetidas na mesma seção transversal, tipicamente de indivíduos ou empresas em aplicações de microeconomia, observadas por vários períodos de tempo.

Ainda para Cameron e Trivedi (2005), a maior vantagem dos dados do painel é o aumento de confiabilidade na estimação. Isto é, o resultado de um aumento do número de observações devido à combinação ou vários períodos de tempo ou de dados para cada indivíduo. 
Dessa forma, diversos estudos utilizam dados em painel para avaliar questões relacionadas ao crescimento econômico, como por exemplo, Barro (2000) e Barro e Sala-I-Martin (2003). Método similar foi utilizado por Sacerdote e Glaeser (2001) para avaliar índices educacionais, motivações às crenças e idade dos membros de determinadas religiões. Barro e McCleary (2003) também utilizaram dados em painel para investigar se o atendimento religioso e as crenças religiosas afetam fatores econômicos, demográficos, políticos, institucionais e o nível de renda per capita.

\subsection{Modelo de Regressão com Dados em Painel}

A tratativa desse modelo ocorreu em três partes; primeiro, os dados foram empilhados de tal forma que possibilitou uma regressão pelo método dos Mínimos Quadrados Ordinários (MQO). ${ }^{8,9}$ De acordo com Cameron e Trivedi (2005), a fórmula usual para as regressões de MQO com dados em painel é via dados empilhados, contudo, essa ferramenta normalmente exagera os ganhos de precisão, levando a erros-padrão subestimados e estatísticas " $t$ " infladas. Desse modo, a solução do problema de heterogeneidade entre os indivíduos pode ocorrer por dois métodos, avaliando por meio dos efeitos fixos ou efeitos aleatórios.

Sobre o modelo de efeitos fixos, segundo Cameron e Trivedi (2005), tratase de uma forma de estimação que permite heterogeneidade individual não observada. Contudo, para Greene (2012), deve-se avaliar a real necessidade da aplicação desse instrumento. Já o raciocínio subjacente do modelo de efeito aleatório é deixar o efeito da heterogeneidade ser tratado pelo erro.

Dadas as particularidades entre os modelos estimados, foi utilizado o teste de Hausman, a fim de se verificar qual é o mais adequado, de efeitos fixos ou aleatórios. De acordo com Cameron e Trivedi (2005), é fundamental realizar a distinção entre os modelos de efeitos fixos e aleatórios na análise de dados em painel, a partir da hipótese nula de que os efeitos individuais são aleatórios. O teste de Hausman verifica se os estimadores são similares (aleatórios) ou divergem entre si (fixos).

8 De acordo com Greene (2012), trata-se de um procedimento utilizado para estudar a relação entre uma variável dependente e uma ou mais variáveis independentes.

9 Para uma apresentação mais completa do procedimento Métodos dos Mínimos Quadrados Ordinários (MQO), ver Greene (2012). 
Para obter estimações mais concisas, faz-se necessário que os erros sejam homocedásticos e não haja autocorrelação serial (Greene 2012). De acordo com Cameron e Trivedi (2005), para garantir uma inferência estatística válida quando algumas das hipóteses do modelo de regressão subjacente são violadas, é comum confiar em erros-padrão "robustos". Dessa forma, os erros- padrão que são obtidos por auxílio desse estimador são consistentes e os resultados obtidos por este trabalho não violam essas hipóteses.

Assim, o trabalho consistiu em estimar e apresentar os resultados advindos dos três modelos: (i) dados empilhados; (ii) efeitos fixos e (iii) efeitos aleatórios, com base no teste $\mathrm{F}$ restrito e no teste de Hausman para constatar qual possui maior aplicabilidade. Dessa forma, a próxima seção apresenta o modelo empírico do presente estudo.

\subsection{Banco de Dados}

Assim como mostrado anteriormente, o modelo empírico proposto é inspirado na metodologia proposta por Mankiw, Romer e Weil (1992), e utilizou-se como base os municípios do Brasil nos anos de 1991, 2000 e 2010.

Contudo, existe uma dificuldade em analisar todos os municípios do país nos anos estabelecidos, pois em 1991 haviam apenas 4491 municípios, sendo que até 2010 houve a criação de 1073, perfazendo 5564. Para a solução desse problema, utilizou-se a metodologia das Áreas Minimamente Comparáveis (AMC), proposta por Reis et al. (2011), em complemento com o trabalho de Ehrl (2017), os quais fundamentam que tem como finalidade compatibilizar as divisões político-administrativas apresentadas nos vários Censos para possibilitar a construção de painéis de dados econômicos municipais. Essa abordagem abre perspectiva para novas análises da economia brasileira e cria arcabouços para estudos inauditos sobre o processo de desenvolvimento econômico brasileiro.

De acordo com Reis et al. (2011), as AMC são geradas por meio da junção das áreas dos municípios alterados ou criados. Portanto, não se referem a uma divisão política ou administrativa, mas simplesmente à área agregada do menor número de municípios necessários para que as comparações intertemporais sejam geograficamente consistentes. 
Desse modo, a base de dados utilizada foi construída por meio dos microdados dos Censos Demográficos de 1991, 2000 e 2010, elaborado pelo IBGE, os quais consistem no menor nível de desagregação dos dados de uma pesquisa e retrata o conteúdo dos questionários, preservando o sigilo estatístico com vistas a não individualização das informações (IBGE 2018).

Os dados foram ponderados com base no peso amostral de cada indivíduo, isto é, sua representatividade na população, dessa forma, retrata uma análise populacional. Alicerçado na metodologia de Reis et al. (2011), com o intuito de analisar a relação municipal, as observações foram agregadas com base nas áreas mínimas comparáveis para os municípios do Brasil, contabilizando 4267 observações em cada período, perfazendo uma amostra total de 12801 observações.

Para classificação das religiões, as mesmas foram dividas de acordo com a classificação de religiões dos Censos Demográficos, ${ }^{10}$ e para retratar o crescimento econômico e as outras variáveis de interesse, foi coletado na base de dados disponibilizada pelo Atlas (2018). Assim, a próxima seção detalha de forma minuciosa o modelo empírico aplicado.

\subsection{Modelo Empírico}

A partir das fundamentações contidas nas seções anteriores, os dados em painel para regressão dos municípios brasileiros podem ser representados pela Equação (7).

$$
\begin{gathered}
\ln Y_{i t}=\beta_{0}+\beta_{1} \ln K_{i t}+\beta_{2}(n+g+\delta)_{i t}+\beta_{3} \ln H_{2}+ \\
\beta_{4} \ln H_{3}+\beta_{5} \ln P_{-} P+\beta_{5} \ln P_{-} T+\mu_{i t} \\
i=1,2, \ldots ., 4267 \\
t=1,2,3
\end{gathered}
$$

Em que a Renda per capita $\left(Y_{i t}\right)$ é explicada pelo Capital Fixo per capita $\left(K_{i t}\right)$, pela taxa de crescimento populacional e tecnológico e pela depreciação $n+g+\delta$, Capital Humano $2\left(H_{2 i t}\right)$, Capital Humano $3\left(H_{3 i t}\right)$, a proporção de protestantes tradicionais $\left(P_{-} T_{i t}\right)$ e a proporção de Protestantes

10 O Anexo 1 apresenta a classificação utilizada. 
pentecostais $\left(P_{-} P_{i t}\right)^{11}$ e o resíduo $\mu_{t}$. Para todo "i" representando as áreas mínimas comparáveis, o que totaliza 4267 AMC e para " $t$ " os anos de 1991, 2000 e 2010. Os " $\beta$ " são os coeficientes de cada variável que serão estimados e os símbolos "ln" indicam que as séries de dados estão em logaritmo natural, tornando possível a interpretação via elasticidades.

A variável dependente renda per capita é a mesma utilizada para elaboração do IDHM, na dimensão renda, a qual foi extraída do Atlas (2018). A seleção dessa variável é relevante em virtude de que o critério utilizado é a auferido em dólares por Paridade Poder de Compra (PPC), isto é, a renda média dos moradores do município com correções que possibilitem sua comparação (PNUD 2013).

Como proxy para capital físico, utilizou-se o estoque de capital residencial per capita, ${ }^{12}$ a preços do ano 2000, calculado pelo IPEA (2018), descrito no texto para discussão de REIFF e REIS (2016). A variável selecionada é adequada para o objetivo em questão e utilizada também com a mesma finalidade em diversos estudos como os de Ferreira, Ellery e Gomes (2008) e Firme e Simão Filho (2014).

Em referência a taxa $(n+g+\delta)_{i t}$, para o crescimento populacional $(n)$, obteve-se dados dos Censos. Já para os valores $(g+\delta)$, considerou-se 0,05, o que de acordo com Mankiw, Romer e Weil (1992) é um valor razoável para considerar a alteração dessas variáveis.

Por meio dos microdados do censo de 1991, 2000 e 2010, foram coletados os dados sobre escolaridade de pessoas acima de 25 anos, os quais foram utilizados como proxy para Capital Humano $\left(H_{i t}\right)$, divido em três categorias, $\left(H_{1 i t}\right)$ para pessoas sem instrução e ensino fundamental incompleto, $\left(H_{2 i t}\right)$ para os indivíduos com ensino fundamental completo e médio incompleto e $\left(H_{3 i t}\right)$ para os com ensino médio completo ou educação superior, para evitar o problema de perfeita colinearidade, a variável $\left(H_{1 i t}\right)$ foi omitida da regressão.

11 As informações acerca da religiosidade no Brasil foram extraídas dos Censos de 1991, 2000 e 2010.

12 O IPEA calcula essa variável apenas até o ano de 2000. Assim, para o valor do capital residencial no ano de 2010, utiliza-se o valor de 2000, com o acréscimo da taxa de crescimento do período de 1991 a 2000, considerando que a trajetória de crescimento no período de 2000 e 2010 foi semelhante à de 1991 a 2000. Assim, embora não seja o procedimento mais adequado, satisfaz as necessidades deste trabalho, sob um cenário de escassez de dados. 
A variável representativa para a proporção de protestantes $\left(P_{-} P_{i t}\right)$ e $\left(P_{-} T_{i t}\right)$, foram ponderadas de acordo com a classificação de religiões dos Censos Demográficos elaborada pelo IBGE e o Instituto Superior de Estudos da Religião - ISER, sendo evangélica (protestante) e católicos, assim como apresentada no Anexo 1.

Inicialmente, cogitou-se a possibilidade de incluir a variável proporção de católicos para verificar o impacto da redução da predominância religiosa da Igreja Católica. Contudo, as religiões católicas e protestantes são predominantes e isso faz com que exista uma forte correlação, o que leva a distorções nas estimativas, dado a alta multicolinearidade. Assim, optou-se por excluir essa variável do modelo, e analisá-la apenas de forma descritiva.

\section{Resultados e Discussões}

A presente seção apresenta uma análise dos resultados a partir do banco de dados apresentado anteriormente. Com a aplicação do método estatístico, realizaram-se discussões relacionadas com a teoria da economia da religião, abordando os demais estudos supracitados. Desse modo, a próxima seção apresenta uma análise descritiva dos dados do Brasil para os anos de 1991, 2000 e 2010.

\subsection{Análise Descritiva Preliminar}

De acordo com Mariano (2013), o campo religioso brasileiro passou por profundas alterações nos últimos anos. Com a finalidade de dar luz a esta relação, a Tabela 1 apresenta a população brasileira dividida com base em sua respectiva opção religiosa, juntamente com a proporção de religiosos para os anos de 1980, 1991, 2000 e 2010. 
Tabela 1 - Proporção de religiosos no Brasil para os anos de 1980, 1991, 2000 e 2010

\begin{tabular}{|c|c|c|c|c|c|c|c|c|c|c|c|c|c|}
\hline \multicolumn{7}{|c|}{ POPULAÇÃO (MILHÕES) } & \multicolumn{7}{|c|}{ PROPORÇÃO DA POPULAÇÃO } \\
\hline PERÍODO & $\mathbf{P}$ & P_T & P_P & SR & C & 0 & PERÍODO & $\mathbf{P}$ & P_T & P_P & SR & C & 0 \\
\hline 1980 & 7,9 & 4,03 & 3,87 & 1,96 & 106,12 & 3,02 & 1980 & 6,64 & 3,39 & 3,25 & 1,65 & 89,18 & 2,54 \\
\hline 1991 & 13,2 & 4,7 & 8,5 & 6,97 & 122,79 & 3,85 & 1991 & 8,99 & 3,2 & 5,79 & 4,75 & 83,64 & 2,62 \\
\hline 2000 & 26,23 & 7,59 & 18,64 & 12,52 & 12 & 5 & 0 & 15,45 & 4,47 & 10,98 & 7,37 & 74,06 & 3,12 \\
\hline 2010 & 33 & 12,31 & 30,02 & 15,35 & 124,14 & 8,93 & 2010 & 22,19 & 6,45 & 15,74 & 8,05 & 65,08 & 4,68 \\
\hline $\begin{array}{c}\Delta(\%) \\
1980-2010\end{array}$ & 436 & 205 & 675 & 684 & 17 & 196 & $\begin{array}{c}\Delta(\%) \\
1980-2010\end{array}$ & 234 & 90 & 384 & 389 & -27 & 85 \\
\hline
\end{tabular}

Fonte: Elaborado pelos autores a partir dos dados dos censos (2018).

Notas: (i) "P_P" representa protestante pentecostal; "P_T" representa protestante tradicional "C" católico, "SR" sem religião e "OR" outras religiões. (ii) o termo $\Delta$ representa a variação.

É perceptível que a alteração no campo religioso no Brasil foi relevante, os resultados contidos na Tabela 1 permitem visualizar essa relação de forma nítida. Elevou-se substancialmente a proporção da população protestante no Brasil, sobretudo da derivação pentecostal, com ênfase entre os anos de 1991 a 2000, juntamente com o declínio da população católica. As alterações observadas na Tabela 1 refletem uma mudança que começou na década de 1890, quando a população protestante compreendia apenas $1 \%$ da população. Haviam várias barreiras para aqueles que desejavam não ser católicos, e muitas perseguições aos que se declaram não católicos, o que dificultava a vida das pessoas que tentavam migrar para novas religiões.

Outro fator que dificultou a propagação do protestantismo no início do século XX foi o analfabetismo. Em 1950, cerca de 50,58\% da população era analfabeta e, em 1991, era apenas 9,62\% (IBGE 2018a). Em outras palavras, a alfabetização da população contribuiu para a leitura da Bíblia e os hábitos religiosos já não se limitavam ao conhecimento transmitido pela Igreja Católica.

O êxodo rural também foi um advento que contribuiu positivamente para o aumento da diversidade religiosa no Brasil. Os dados do IBGE (2018a) mostram que, em 1950, a taxa de urbanização de 36,1\%. Em 1991, esse se alterou para $75 \%$. Obviamente, a acessibilidade das questões religiosas na cidade era maior, e o conhecimento transmitiu livremente entre as pessoas. Esses fatores justificam a alteração quantitativa do campo religioso brasileiro, visualizado na Tabela 1 e ilustrado pela Figura 1. 
Figura 1 - Variação da proporção da população protestante nas mesorregiões do Brasil para os anos de $1980,1991,2000$ e $2010^{13}$

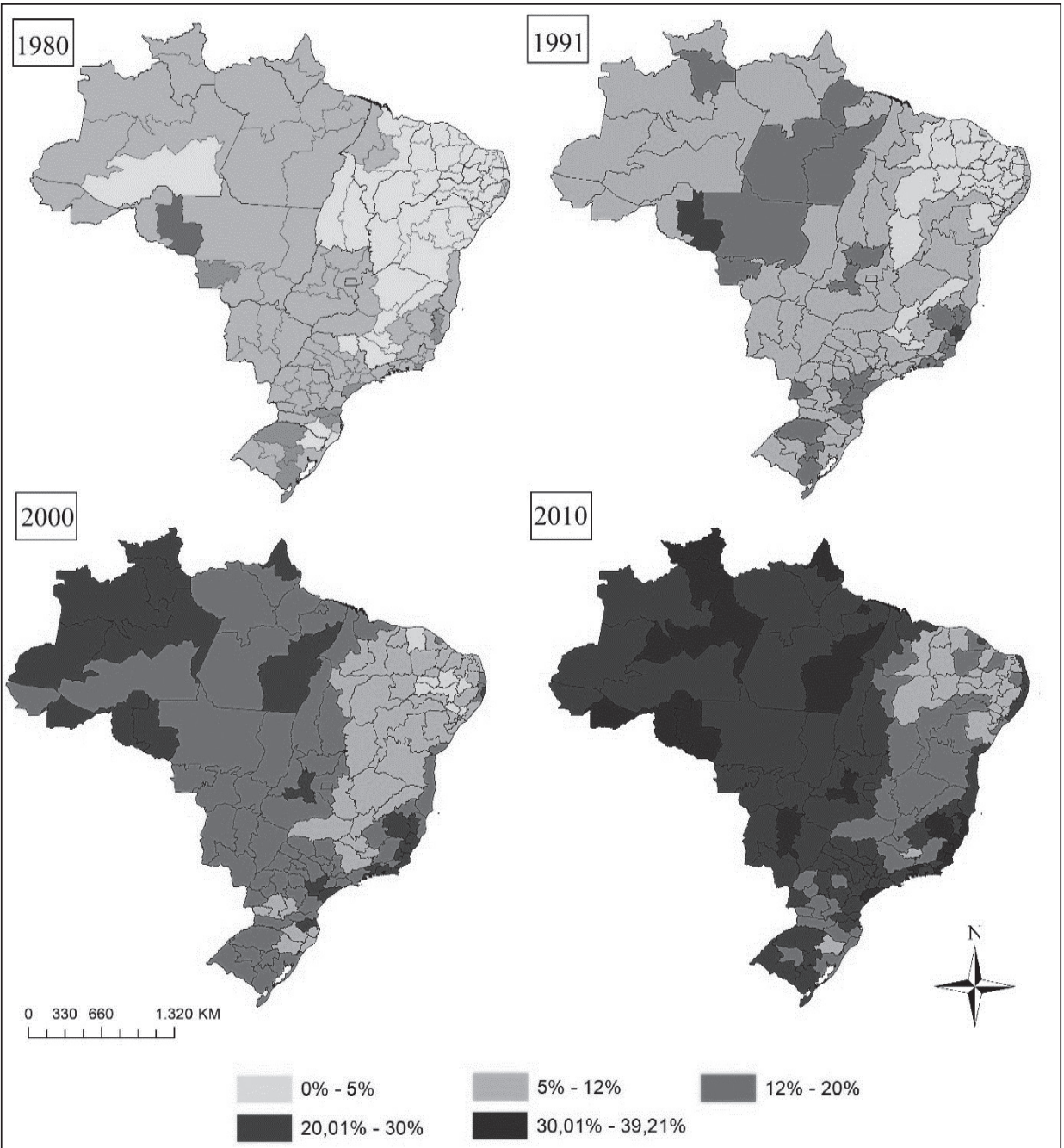

Fonte: Elaborado pelos autores a partir dos dados do IBGE (2018).

Por meio da Figura 1, é possível visualizar, de forma desagregada, a elevação da proporção de protestantes no país, com ênfase para o período de 1991 a 2000, em que o número de protestantes da maior parte das micror-

13 A Figura 1 retrata a variação da população de protestantes nos anos de 1991, 2000 e 2010, com exceção para as mesorregiões do estado do Tocantins no ano de 1991. 
regiões cresceu a uma porcentagem superior a 70\%. ${ }^{14}$ Segundo McCleary (2011), o fator-chave para o declínio do catolicismo, no início dos anos de 1960, foi o posicionamento condenatório da Igreja acerca das formas artificiais de controle de natalidade.

Outro fator relevante é que, em 1980, a maior parte das microrregiões do Brasil apresentava entre $0 \%$ a $5 \%$ de sua população protestante e, para 2010 , esse valor ficou na faixa de $20 \%$ a $30 \%$. De forma complementar, observa-se que, atualmente, a região Norte apresenta a maior quantidade de mesorregiões no extrato máximo selecionado para a proporção de protestantes, acima de 30\%. Já a região Nordeste, a menor proporção de pessoas na faixa de $5,01 \%$ a $12 \%$. A baixa adesão ao protestantismo nesta região pode ser explicada pela baixa escolaridade, com muitas pessoas ainda analfabetas. Além disso, grande parte da população nesta região ainda vive em áreas rurais e não tem acesso às igrejas protestantes.

Os resultados estão de acordo com as afirmações de Neri e Melo (2011), e convergem com a importância da economia da religião prestada por McCleary (2011). De forma sequencial, para uma apresentação detalhada do banco de dados utilizados neste estudo, a Tabela 2 retrata a variação das variáveis analisadas.

Tabela 2 - Média das variáveis utilizadas para o Brasil nos anos de 1991, 2000 e 2010

\begin{tabular}{|c|c|c|c|c|c|}
\hline VARIÁVEIS & $\begin{array}{c}\text { MÉDIA } \\
1991\end{array}$ & MÉDIA 2000 & $\begin{array}{c}\text { MÉDIA } \\
2010\end{array}$ & $\begin{array}{c}\text { VARIAÇÃO } \\
\text { 1991-2000(\%) }\end{array}$ & $\begin{array}{c}\text { VARIAÇÃO } \\
2000-2010(\%)\end{array}$ \\
\hline$Y(R \$)$ & 247,71 & 349,17 & 502,33 & 40,96 & 43,87 \\
\hline CAP, RES, PER CAPITA (R\$) & 2,09 & 3,33 & 3,35 & 59,52 & 0,73 \\
\hline$(\mathrm{n}+\mathrm{g}+\delta)$ & 0,05 & 0,23 & 0,13 & 356,89 & $-41,68$ \\
\hline CAPITAL HUMANO 1(\%) & 88,39 & 81,77 & 68,44 & $-7,49$ & $-16,30$ \\
\hline CAPITAL HUMANO 2(\%) & 5,82 & 9,23 & 13,31 & 58,51 & 44,27 \\
\hline CAPITAL HUMANO 3(\%) & 5,79 & 9,01 & 18,25 & 55,52 & 102,63 \\
\hline P_TRADICIONAL (\%) & 2,29 & 3,03 & 3,28 & 32,38 & 8,05 \\
\hline P_PENTECOSTAL (\%) & 4,78 & 8,13 & 10,95 & 69,99 & 34,70 \\
\hline PROTESTANTE TOTAL & 7,07 & 11,16 & 14,23 & 57,80 & 27,45 \\
\hline CATÓLICO (\%) & 89,03 & 82,36 & 76,13 & $-7,50$ & $-7,55$ \\
\hline
\end{tabular}

Fonte: Elaborado pelos autores a partir dos dados do IBGE e IPEA (2018).

Notas: (i) As variáveis de em (\%) evidenciam a proporção da população nesses indicadores.

14 Ver mais a alteração no campo religioso brasileiro em Mariano (2013). 
É possível visualizar por meio da Tabela 2 que a maioria das variáveis selecionadas na análise deste estudo cresceram no período analisado. Conforme ressaltado anteriormente, é notório que houve uma elevação da renda per capita dos municípios brasileiros, acompanhado do número de protestantes, indicando um sinal favorável da aplicação da teoria de Weber (2013).

Visualiza-se, também, que ocorreu um aumento no estoque de capital residencial per capita de 1991 a 2010, sinalizando um indicativo positivo ao crescimento econômico. Para o nível 1 de capital humano $\left(\mathrm{H}_{1}\right)$, observa-se que se reduziu substancialmente, em virtude da elevação no nível de escolaridade da população brasileira. Em relação aos outros dois níveis de escolaridade Capital Humano $2\left(\mathrm{H}_{2}\right)$ e Capital Humano $3\left(\mathrm{H}_{3}\right)$, nota-se que ambos se elevaram, mas com ênfase ao nível 3, resultado das políticas públicas direcionadas ao ensino superior ocorrida nos últimos anos.

O crescimento da proporção de protestantes no Brasil é notório, conforme pode ser visualizado na Tabela 2 , tanto no ramo tradicional, quanto pentecostal. Mas vale destacar a significativa elevação das denominações pentecostais, principalmente, a partir dos anos de 1990. O declínio da proporção de católicos também é visualizado na Tabela 2, corroborando com os dados mencionados anteriormente. Para aprofundar a tratativa sobre as variáveis desse estudo, a Tabela 3 apresenta desvio padrão, valor máximo e mínimo entre as 4267 áreas minimamente comparáveis do Brasil, para cada uma das variáveis consideradas em 1991, 2000 e 2010.

Tabela 3 - Desvio padrão, valor máximo e mínimo das variáveis

\begin{tabular}{ccccccccccc}
\hline ANO & & Y (R\$) & CAP.RES & $(\mathrm{n}+\mathrm{g}+\delta)$ & H1(\%) & H2(\%) & H3(\%) & P_T(\%) & P_P(\%) & C(\%) \\
\hline \multirow{2}{*}{1991} & DP & 147,29 & 1,84 & 0 & 6,71 & 3,18 & 3,85 & 4,86 & 3,95 & 8,86 \\
& MíN & 43,7 & 0,03 & 0,05 & 48,65 & 0,05 & 0,00 & 0,00 & 0,00 & 18,73 \\
& MÁX & 1185,28 & 17,71 & 0,05 & 99,67 & 19,40 & 36,73 & 77,54 & 28,85 & 100,00 \\
\hline \multirow{2}{*}{2000} & DP & 196,8 & 2,38 & 0,37 & 8,50 & 3,75 & 5,11 & 5,02 & 5,29 & 10,98 \\
& MíN & 69,2 & 0,12 & $-0,47$ & 44,47 & 0,98 & 0,47 & 0,00 & 0,00 & 16,05 \\
& MÁX & 1759,76 & 18,86 & 5,48 & 98,02 & 21,67 & 41,10 & 80,37 & 35,66 & 100,00 \\
\hline \multirow{2}{*}{2010} & DP & 244,45 & 2,39 & 0,15 & 9,05 & 2,80 & 6,95 & 4,43 & 6,22 & 12,69 \\
& Mín & 122,21 & 0,12 & $-0,44$ & 34,31 & 3,05 & 1,69 & 0,00 & 0,00 & 21,04 \\
& MÁX & 2043,74 & 18,92 & 1,87 & 93,48 & 28,80 & 52,96 & 69,26 & 43,38 & 98,84 \\
\hline
\end{tabular}

Fonte: Elaborado pelos autores a partir dos dados do IBGE (2018). 
De forma geral, através do desvio padrão apresentado na Tabela 3, observase grande disparidade nas variáveis selecionadas, o que reflete a heterogeneidade dos municípios. Novamente, conforme ressaltado por Mariano (2013), constata-se uma elevação dos máximos e redução dos mínimos, da proporção de protestante e da renda per capita, com ênfase nas denominações protestantes. Em relação aos valores máximos e mínimos das variáveis utilizadas no modelo, os Anexos 4 e 5 apresentam os municípios que se destacaram.

De modo geral, o Anexo 2 possibilita um panorama detalhado sobre a relação entre as variáveis do modelo. No que se refere à religiosidade, é possível perceber uma relação linear positiva entre o protestantismo e a renda, e negativo para o catolicismo. Com base nas variáveis que refletem os índices educacionais, proxies de Capital Humano, para variável $\mathrm{H}_{1}$ a relação foi negativa e para outras duas positivas, assim como o que foi fundamentado por Mankiw, Romer e Weil (1992). Algumas outras variáveis explicativas parecem estar fortemente correlacionadas, o que pode ser um indício de multicolinearidade, que ocorre no caso de duas ou mais variáveis explicativas estarem fortemente correlacionadas, o que pode gerar vieses bastantes expressivos nos parâmetros estimados (Bueno 2011). Dessa forma, a próxima seção apresentará os resultados das regressões, assim como os testes de robustez do modelo.

\subsection{Resultados Da Regressão}

Conforme constatado anteriormente por meio do Anexo 2, há uma forte correlação entre as variáveis explicativas do modelo, o que é indício do problema de multicolinearidade. Com a finalidade de verificar formalmente esta relação, aplica-se o teste Fator de Inflação de Variância que mostra como a variância de um estimador é inflada pela presença da multicolinearidade (Greene 2012).

Assim, por meio do Anexo 3, evidencia-se que as variáveis não apresentam multicolinearidade, pois, de acordo com Greene (2012), apenas valores superiores a 10 no teste VIF são indicativos desse problema. Resultado importante para que se possa obter boas inferências do modelo econométrico. 
Desse modo, com base no que foi apresentado anteriormente, a Tabela 4 apresenta os resultados das regressões.

Tabela 4 - Resultado das regressões para MQO, efeitos, efeitos fixos e efeitos aleatórios

\begin{tabular}{|c|c|c|c|c|c|c|c|}
\hline Var & MQO & Efeitos Fixos & Efeitos Aleatórios & Var & MQO & Efeitos Fixos & Efeitos Aleatórios \\
\hline$K_{i t}$ & $\begin{array}{c}0,31 \\
(0,005)^{* * *}\end{array}$ & $\begin{array}{c}0,218 \\
(0,011)^{\star \star *}\end{array}$ & $\begin{array}{c}0,294 \\
(0,005)^{* * *}\end{array}$ & $\mathrm{~K}_{\mathrm{it}}$ & $\begin{array}{c}0,313 \\
(0,005)^{* * *}\end{array}$ & $\begin{array}{c}0,233 \\
(0,01)^{* * *}\end{array}$ & $\begin{array}{c}0,295 \\
(0,005)^{* * *}\end{array}$ \\
\hline $\mathrm{n}+\mathrm{g}+\delta_{\mathrm{it}}$ & $\begin{array}{l}-0,018 \\
(0,01)^{* * *}\end{array}$ & $\begin{array}{l}-0,027 \\
(0,008)^{* * *}\end{array}$ & $\begin{array}{l}-0,031 \\
(0,008)^{* * *}\end{array}$ & $\mathrm{n}+\mathrm{g}+\delta_{\text {it }}$ & $\begin{array}{l}-0,025 \\
(0,01)^{*+*}\end{array}$ & $\begin{array}{l}-0,022 \\
(0,008)^{*+*}\end{array}$ & $\begin{array}{c}-0,03 \\
(0,007)^{* * *}\end{array}$ \\
\hline $\mathrm{H}_{2 \mathrm{it}}$ & $\begin{array}{c}0,191 \\
(0,014)^{* *}\end{array}$ & $\begin{array}{c}0,009 \\
(0,012)^{* * *}\end{array}$ & $\begin{array}{c}0,05 \\
(0,012)^{* * *}\end{array}$ & $\mathrm{H}_{2 \mathrm{it}}$ & $\begin{array}{c}0,179 \\
(0,013)^{*+*}\end{array}$ & $\begin{array}{c}0,235 \\
(0,011)^{* *}\end{array}$ & $\begin{array}{c}0,055 \\
(0,011)^{* * *}\end{array}$ \\
\hline $\mathrm{H}_{3 \mathrm{it}}$ & $\begin{array}{c}0,253 \\
(0,01)^{* * *}\end{array}$ & $\begin{array}{c}0,375 \\
(0,009)^{* * *}\end{array}$ & $\begin{array}{c}0,342 \\
(0,009)^{* * *}\end{array}$ & $\mathrm{H}_{3 \mathrm{it}}$ & $\begin{array}{c}0,252 \\
(0,009)^{* * *}\end{array}$ & $\begin{array}{c}0,371 \\
(0,008)^{*+*}\end{array}$ & $\begin{array}{c}0,334 \\
(0,008)^{* * *}\end{array}$ \\
\hline$P_{-} T_{i t}$ & $\begin{array}{c}0,026 \\
(0,002)^{*+*}\end{array}$ & $\begin{array}{c}0,013 \\
(0,003)^{* * *}\end{array}$ & $\begin{array}{c}0,02 \\
(0,003)^{* * *}\end{array}$ & $\mathrm{P}_{\mathrm{it}}$ & $\begin{array}{c}0,076 \\
(0,004)^{*+*+}\end{array}$ & $\begin{array}{c}0,065 \\
(0,007)^{*+*}\end{array}$ & $\begin{array}{c}0,067 \\
(0,005)^{* * *}\end{array}$ \\
\hline$P_{-} P_{i t}$ & $\begin{array}{c}0,035 \\
(0,005)^{* * *}\end{array}$ & $\begin{array}{c}0,072 \\
(0,006)^{*+*}\end{array}$ & $\begin{array}{c}0,046 \\
(0,005)^{* * *}\end{array}$ & & & & \\
\hline Const & $\begin{array}{c}6,802 \\
(0,021)^{*+*}\end{array}$ & $\begin{array}{c}6,772 \\
(0,027)^{*+*} \\
\end{array}$ & $\begin{array}{c}6,689 \\
(0,018)^{*+*} \\
\end{array}$ & Const & $\begin{array}{c}6,745 \\
(0,02)^{*+*}\end{array}$ & $\begin{array}{c}6,683 \\
(0,023)^{* * *} \\
\end{array}$ & $\begin{array}{c}6,632 \\
(0,016)^{* *+}\end{array}$ \\
\hline Obs & 11699 & 11699 & 11699 & Obs & 12741 & 12741 & 12741 \\
\hline $\mathrm{R}^{2}$ & 0,8158 & 0,8032 & 0,812 & $\mathrm{R}^{2}$ & 0,8196 & 0,8032 & 0,8165 \\
\hline Teste F & 4664,73 & 3384,81 & & Teste F & 6602,81 & 4333,72 & \\
\hline Wald chi ${ }^{2}$ & & & 24781,44 & Wald chi ${ }^{2}$ & & & 24781,44 \\
\hline Hausman & & 609,51 & & Hausman & & 601,43 & \\
\hline$F$ restrito & 5,51 & & & $F$ restrito & 5,63 & & \\
\hline
\end{tabular}

Fonte: Elaborado pelos autores a partir dos dados do IBGE e IPEA (2018).

Notas: (i) $\left({ }^{* * *}\right)$ Significativo a $1 \%$; $\left.{ }^{* *}\right)$ Significativo a 5\%; $\left({ }^{*}\right)$ Significativo a $10 \%$. (ii) os valores na parte inferior dos coeficientes, entre parênteses, retratam os erros-padrão. (iii) os resultados são robustos à heterocedasticidade. (iv) o $\mathrm{R}^{2}$ dos modelos de MQO, de efeitos fixos e aleatórios sem a variável da religião foram inferiores.

Os resultados contidos na Tabela 4 apontam que todas as estimativas foram boas, em virtude de a maioria das variáveis serem significantemente diferente de zero e pelos altos valores do $\mathrm{R}^{2}$, os quais indicam que o modelo possui alto poder explicativo. Também é possível observar que os modelos possuem quantidades distintas de observações. Isso ocorreu porque algumas observações foram perdidas por apresentarem valores zerados no período, como as proporções de protestantes tradicionais em alguns municípios. 
Outra constatação que se pode realizar por meio do $\mathrm{R}^{2}$ é que a inclusão da variável religião aumenta o poder de explicação do modelo, porque as regressões realizadas sem a variável de religião, apontam $u m R^{2}$ ajustado inferior ao retratado na Tabela 4.

Ainda de modo geral, como sugerido pelo modelo de Solow (1956), e em outras formulações descendentes, há uma grande importância na proxy utilizada para Capital $\left(K_{i t}\right)$, em virtude dos coeficientes encontrados. É perceptível que uma maior dotação do fator de produção Capital $\left(K_{i t}\right)$ contribui para o nível de renda per capita. Embora os modelos de crescimento tenham se aprimorado, essa afirmação é mantida e pode ser constatada nos trabalhos de Solow (1956), Schultz (1961), Becker (1962), Huntington (1996), Landes (1998) e o de Inglehart e Baker (2000).

Entretanto, de forma similar ao que foi abordado nos conceitos teóricos, há autores como Mankiw, Romer e Weil (1992), que consideram que a variável Capital Humano deve ser incluída de modo explícito no modelo formal. Dessa forma, as proxies utilizadas para Capital Humano mostram um resultado relevante, em virtude que $\mathrm{H}_{2 i t}$ e $\mathrm{H}_{3 i t}$ retratam um impacto positivo e $\mathrm{H}_{1 i t}$, que representa o menor nível de escolaridade, uma relação negativa (Tabela 4 e Anexo 2).

Sobre os resultados da religiosidade, os coeficientes sugerem que a relação entre a alteração do campo religioso brasileiro e o nível de renda per capita é positiva, assim como fundamentado por Barro e McCleary (2003), McCleary (2011), Weber (2013), entre outros autores, e contrapondo os argumentos de Zalewski de Souza (2007). ${ }^{15}$ Portanto, considerando que a religião interfere no comportamento do indivíduo e a grande alteração no contexto religioso brasileiro, faz-se necessário elaborar estudos econômicos a fim de acompanhar essa transição e oferecer embasamentos científicos para possíveis adequações legislativas e políticas públicas.

Para um aprimoramento da tratativa dos resultados, assim como fundamentado na seção metodológica, faz-se necessário avaliar qual modelo apresenta os melhores resultados. $O$ teste $F$ restrito, com $H_{0}$ todos os interceptos diferenciais são iguais a zero, é um teste formal entre o Modelo de Efeitos Fixos e o com dados Empilhados. O valor encontrado desse teste indica que o modelo de Efeitos Fixos é superior ao de dados empilhados.

${ }^{15}$ Esse autor justifica que embora seja importante analisar a formação religiosa, ínfimos seriam os impactos advindos de uma transição religiosa no atual contexto da América Latina. 
Para avaliar em relação ao modelo de Efeitos Aleatórios, aplica-se o teste de Hausman, e a partir do valor encontrado desse teste tem-se que o modelo que produz as melhores estimativas é o de Efeitos Fixos.

O modelo de Efeitos Fixos apresenta resultados importantes para este estudo. Inicialmente, visualiza-se que à medida que aumenta a proporção de protestantes, maior o valor esperado para o nível de renda dos municípios, o que está de acordo com as análises anteriormente realizadas e o que a teoria prediz nos estudos empíricos supracitados.

Sobre os coeficientes encontrados para o modelo de efeitos fixos, inferese que para o aumento de $1 \%$ da proxy de capital fixo " $K$ ", espera-se uma elevação de $0,31 \%$ no nível de renda per capita, impactando positivamente tal como nos estudos de Solow (1956), Mankiw, Romer e Weil (1992), Ferreira, Ellery e Gomes (2008) e Firme e Simão Filho (2014).

Sobre os coeficientes da taxa de desconto, " $n+g+\delta$ ", os resultados indicam que os valores são negativos, assim como proposto por Mankiw, Romer e Weil (1992) e encontrados por outros autores.

Já em relação à variável que representa a proporção de pessoas com ensino fundamental completo e ensino médio incompleto " $\mathrm{H}_{2}$ ", a um nível de significância de 5\%, também foi encontrada uma relação positiva

Nesse sentido, em relação à variável que representa pessoas com ensino médio completo ou ensino superior " $\mathrm{H}_{3}$ ", o coeficiente encontrado é expressivo, e mostra que para uma elevação de $1 \%$ na variável dependente, espera-se uma elevação média de $0.37 \%$ na renda per capita.

Por fim, para a variável de proporção de pessoas protestantes, tanto as ramificações tradicionais, quanto a derivação pentecostal, impactam positivamente, com ênfase na denominação pentecostal, pois apresentou um coeficiente maior, indicando um impacto mais elevado, convergindo com as análises iniciais (Anexo 2) e com os estudos de Martin (1990), Almeida (2004), Freston (2001) e Marcantonio Junior (2016). Em relação aos coeficientes, para o aumento de $1 \%$ na proporção de protestantes totais, estima-se uma elevação de $0,06 \%$ na renda per capita. Para a elevação de $1 \%$ na proporção de protestantes tradicionais e pentecostais, o valor estimado para o crescimento da renda per capita é de $0,01 \%$ e $0,07 \%$, respectivamente. 
Os coeficientes encontrados podem, inicialmente, ser considerados pequenos; no entanto, faz-se necessário observar a grande alteração visualizada no Brasil, retratada na Tabela 1. A partir da constatação da alteração ocorrida no país e os resultados das regressões, fica evidente que a transição no campo religioso brasileiro é um fator que influenciou positivamente para o crescimento no nível de renda per capita e se trata de uma variável que deve ser incluída nas análises que relacionam o crescimento econômico. Resultado similar foi encontrado nos resultados de Bernardelli, Gomes e Michellon (2017) em uma análise para o Brasil em 2010.

Assim, este estudo foi pertinente em virtude de sugerir o acréscimo de uma variável relevante nas análises sobre o crescimento econômico de municípios, regiões, estados e até de países, ou seja, a religião não opera somente em questões espirituais, mas também molda o ser humano e determina seus hábitos de consumo, trabalho e renda, alterando a forma de organização social.

\section{Conclusão}

Por se tratar de uma temática relevante, diversos autores buscam explicar os determinantes do crescimento econômico. Com essa finalidade, distintas variáveis são relacionadas como: estoque de trabalho, capital fixo e humano, nível tecnológico, grau de instrução e até mesmo questões culturais da população. No entanto, são poucos os estudos que relacionam a influência da religião sobre o crescimento econômico e sua respectiva importância para a sociedade. Dessa forma, fica claro que se trata de uma questão relevante e pouco debatida no meio econômico brasileiro.

Em outas palavras, considerando a significativa alteração no campo religioso brasileiro, estudos que busquem avaliar o impacto econômico desse movimento são fundamentais, principalmente no que diz respeito ao declínio do catolicismo, crescimento da participação dos protestantes tradicionais e pentecostais e da elevação da proporção de pessoas sem religião, visualizada em todas as regiões do país. 
Os resultados da mensuração aplicada neste estudo indicam que a elevação da proporção de protestantes pentecostais e tradicionais constatada no Brasil foi importante para o aumento no nível de renda. Ainda, sobre o contexto religioso, os resultados apontam evidências favoráveis às teorias de autores que sugerem que a ética protestante favorece o desempenho econômico dos países e que um maior percentual de protestantes contribui para um maior nível de renda per capita, com ênfase na denominação pentecostal, que apresentou maior crescimento nos últimos anos.

Além das fundamentações teóricas apresentadas que sustentam esse resultado, observa-se que as igrejas neopentecostais, que obtiveram crescimentos substanciais nos últimos anos, enfatizam fortemente o acúmulo de riquezas e o empreendedorismo. Dessa forma, fornecem fortes incentivos ao trabalho e ao ganho de dinheiro, proporcionando aumento de produtividade e, consequentemente, o crescimento econômico.

Outra variável relevante encontrada foi a elevação nos níveis educacionais, o que corroborou com estudos que relacionam a importância do Capital Humano, principalmente em relação ao nível superior, que apresentou maior coeficiente das regressões, representando um impacto maior

Para pesquisas futuras, a sugestão é de que seja realizada a inclusão dos quatro últimos censos, 1980, 1991, 2000 e 2010, com a finalidade de verificar minuciosamente tais relações. Outra sugestão é verificar a relação espacial entre as variáveis e suas implicações nos resultados encontrados neste estudo. O contexto ainda apresentado neste trabalho limitou-se a análise da migração do catolicismo para o protestantismo, mas não se pode ignorar o crescimento das pessoas sem religião, que se trata de uma temática de importante análise, a qual, sem dúvida, será objetivo de análise em futuros trabalhos sobre a Economia da religião. 


\section{Referências}

Almeida, R. 2000. “Religião na metrópole paulista”. Revista Brasileira de Ciências Sociais”. Revista Brasileira de Ciências Sociais 19 (56): 15-17.

Almeida, R. 2004. Religião na metrópole paulista. Revista Brasileira de Ciências Sociais 19 (56): 15-27.

Alves, J. E. D., Cavenaghi, S. M.; Barros, L. F. W. 2014. “A transição religiosa brasileira e o processo de difusão das filiações evangélicas no Rio de Janeiro". Horizonte 12 (36): 1055-1085.

Anuatti-Neto, F; Narita, R. T. 2004. "A influência da opção religiosa na acumulação de capital humano: um estudo exploratório”. Estudos Econômicos (São Paulo) 34 (3): 453-486.

ATLAS DO DESENVOLVIMENTO HUMANO NO BRASIL (ATLAS). "Dados para o Brasil". Disponível em $<$ http://www.atlasbrasil.org.br/>. Acesso em: 10 mai. 2018.

Azzi, C., Ehrenber, R. G. 1975. "Household Allocation of Time and Church Attendance". Journal of Political Economy 83 (1): 27-56.

Barro, R. J. 2000. "Inequality and Growth in a Panel of Countries". Journal of Economic Growth, local 5 (1): 5-32.

Barro, R. J., Mccleary, R. M. 2003. "Religion and Economic Growth across Countries". American Sociological Review 68 (5): 760-814.

Barro, R. J., Sala-I-Martin, X. 2003. "Economic Growth". 2. ed. edition. Massachusetts: Institute of Technology, $654 \mathrm{p}$.

Becker, G. S. "Investment in Human Capital: 1962. 'A Theoretical Analysis"'. Journal of Political Economy70 (5) 9-49.

Becker, S. O., Woessmann, L. "Was Weber Wrong? A Human Capital Theory of Protestant Economic History". Quarterly Journal of Economics 124 (2): 531-596.

Bernardelli, L. V., Gomes, C. E., Michellon, E. 2017. "Religião e desenvolvimento econômico: uma análise para o Brasil à luz do catolicismo e protestantismo". Revista de Economia Mackenzie 13 (1): 164-186.

Bueno, R. L. S. 2011. "Econometria de Séries Temporais". 2. ed. São Paulo: Cengage Learning, 360 p.

Cameron, A. C., Trivedi, P. K. 2005. "Microeconometrics: methods and application”. Cambridge: Cambridge University Press. 1058 p.

Ehrl, P. 2017. "Minimum comparable areas for the period 1872-2010: an aggregation of Brazilian municipalities". Estudos Econômicos (São Paulo) 47 (1) 215-229.

Ekelund Junior, R. B., Hébert, R. F., Tollison, R. D. 2002. “An Economic Analysis of the Protestant Reformation. Journal of Political Economy" 110(3): 646-671.

Ferreira, P. C., Ellery Jr, R., Gomes, V. 2008. "Produtividade agregada brasileira (1970-2000): declínio robusto e fraca recuperação". Estudos Econômicos (São Paulo) 38 (1): 31-53.

Firme, V. A. C., Simão Filho, J. “Análise do crescimento econômico dos municípios de minas gerais via modelo MRW (1992) com capital humano, condições de saúde e fatores espaciais, 1991-2000”. Economia Aplicada 18 (4): 679-716.

Freston, P. 2001. "Evangelicals and Politics in Asia, Africa and Latin America". Cambridge University Press, 214 p. Gaarder, J., Hellern, V., Notaker, H. 2005. "O Livro das Religiões”. São Paulo: Companhia das Letras. 336 p. Greene, W. 2012. "Econometric analysis". 7ed. New York: Pearson, 1241 p.

Huntington, S. P. 1996. "The Clash of Civilizations and the Remaking of World Order". New York: Simon \& Schuster, $367 \mathrm{p}$.

IBGE. “Anuário Estatístico do Brasil 2016”. v. 76. Rio de Janeiro. p. 457. Disponível em: < https://biblioteca. ibge.gov.br/visualizacao/periodicos/20/aeb_2016.pdf>. Acesso em: 10 mai. $2018 \mathrm{a}$. 
IBGE. Instituto Brasileiro de Geografia e Estatística. Governo Federal (Org.). "Censo Demográfico 2010: Resultados gerais da amostra. 2010". Disponível em: $<$ http://www.ibge.gov.br/home/estatistica/populacao/censo2010/ resultados_gerais_amostra/resultados_gerais_amostra tab_uf_microdados.shtm>. Acesso em: 10 mai. 2018.

Inglehart, R., Baker, W. E. 2000. "Modernization, Cultural Change, and the Persistence of Traditional Values". American Sociological Review 65 (1): 19-51.

IPEA - INSTITUTO DE ECONOMIA APLICADA. "Base de Dados do Brasil". Disponível em: <http://www. ipeadata.gov.br/>. Acesso em: 10 mai. 2018.

Keyes, Charles F. 2002. "Weber and Anthropology. Annual Review of Anthropology" 31 (1): 233-255.

Landes, D. 1998. "The Wealth and Poverty of Nations: Why some are so Rich and some so Poor". London: W. W. Norton \& Company, $676 \mathrm{p}$.

Laveleye, E. 1985. "Do Futuro dos Povos Católicos: Estudo de Economia Social”. 2ed. Tradução por Dr. Miguel Vieira Ferreira. São Paulo: Casa Editora Presbiteriana, 98 p.

Lenski, G. E. 1961. “The religious factor: a sociological study of religion's impact on politics, economics, and family life". Garden City: Doubleday, 448 p.

Lutero, M. 2004. "Martinho Lutero: V 1 - Os Primórdios Escritos de 1517 a 1519”. 2. ed. Canoas: Editora da Ulbra, 469 p. (Obras Selecionadas). Comissão Interluterana de Literatura São Leopoldo.

Mankiw, N. G., Romer, D.; Weil, D. 1992. "A contribution to the empirics of economic growth". The Quarterly Journal of Economics 107(2): 407- 437.

Marcantonio Junior, A. 2016. "Income Shocks and Pentecostal Upsurge in Brazil (1991-2000). 2016". 56 f. Dissertação (Mestrado) - Curso de O Programa de Pós-graduação em Economia, Universidade Federal do Rio de Janeiro, Rio de Janeiro.

Mariano, R. 2013. "Mudanças no campo religioso brasileiro no Censo 2010". Debates do NER (UFRGS. Impresso) 14 (1): 119-137.

Mariano, R. 2011. "Sociologia do crescimento pentecostal no Brasil: um balanço. Perspectiva Teológica" 43 (119): 11-36.

Martin, D. 1990. "Tongues of fire: the explosion of Protestantism in Latin America”, Oxford: Blackwell. 352 p.

Mccleary, R. M. 2011. "The Oxford Handbook of the Economics of Religion”. New York: Oxford University Press, $432 \mathrm{p}$.

Michellon, E. 2006. "O dinheiro e a natureza humana: como chegamos ao moneycentrismo?". Rio de Janeiro: MK Editora, $256 \mathrm{p}$.

Michellon, E., Santos, R. G., Suzuki, W. O. 2012. “A Influência da Religião no Desenvolvimento dos Países”. In: IV Conferência Internacional de História Econômica \& VI Encontro de Pós-Graduação em História Econômica, São Paulo, USP.

Neri, M. C., Melo, L. C. C. 2011. "Novo Mapa das Religiões”. Horizonte. Revista de Estudos de Teologia e Ciências da Religião 9 (23): 637-673.

Olson, M. Jr. 1996. "Big Bills Left on Sidewalk: Why Some Nations Are Rich, and Others Poor”. Journal of Economic Perspectives 10 (1): 3-24.

PEW RESEARCH CENTER. Spirit and Power - A 10-Country Survey of Pentecostals. 2006. Disponível em: $<$ http://www.pewforum.org/2006/10/05/spirit-and-power/>. Acesso em: 10 mai. 2018.

Reiff, L. O., Reis, E. J. 2016. “Estoque de capital em residências no Brasil (1970-1999)”. Texto para discussão 2265.

Reis, E. et al. 2011. “Áreas mínimas comparáveis para os períodos intercensitários de 1872 a 2000”. In: I Simpósio Brasileiro de Cartografia Histórica, 2011, Parati. I Simpósio Brasileiro de Cartografia Histórica. Belo Horizonte: CRCH.

Romer, D. 2012. "Advanced Macroeconomics", 4 ed. University of California, Berkeley: McGraw-Hill, 738 p. Sacerdote, B., Glaeser E. L. 2001. "Education and Religion”. National Bureau of Economic Research, working paper $n^{\circ} 8080$. 
Schultz, T. W. "Investment in Human Capital. 1961. The American Economic Review" 51 (1): 1-17.

Smith, A. 2007. "An Inquiry into the Nature and Causes of the Wealth of Nations". New York: Metalibri, 754p. Smith, A. 2010. "The theory of moral sentiments". Penguin Classics, 544 p.

Solow, R. M.A. 1956. "Contribution to the Theory of Economic Growth". Quarterly Journal of Economics 70 (1): 65-94.

Stark, R. 1984. "Religion and conformity: Reaffirming a sociology of religion". Sociological Analysis 45 (4) 273-282.

Stark, R., Glock, C, Y. 1968. "American piety: the nature of religious commitment. Los Angeles": University of California Press, 1968. 230 p.

Stoll, D. 1990. "Is Latin America turning protestant?: the politics of evangelical growth". Berkeley: University of California Press.

Weber, M. 2013. “A ética protestante e o espírito do capitalismo”. São Paulo: Martin Claret, 2013. 238 p.

Woodberry, R. D. 2011. "Religion and the Spread of Human Capital and Political Institutions". In: Mccleary, R. M. (Org). The Oxford Handbook of the Economics of Religion. New York: Oxford University Press,. 432 p. WORLD BANK (Org.). GDP per capita, PPP (current international \$). Disponível em: $<$ https://data.worldbank. org/indicator/NY.GDP.PCAP.PP.CD?view=chart>. Acesso em: 10 mai. 2018.

Zalewski De Souza, N. L. 2007. "Religião e desenvolvimento: uma análise da influência do catolicismo e protestantismo no desenvolvimento econômico da Europa e América". Dissertação (Mestrado) - Programa de Pós-Graduação da Faculdade de Economia da Pontifícia Universidade Católica do Rio Grande do Sul. Porto Alegre. 


\section{Anexos}

\section{Anexo 1 - Classificação de religiões}

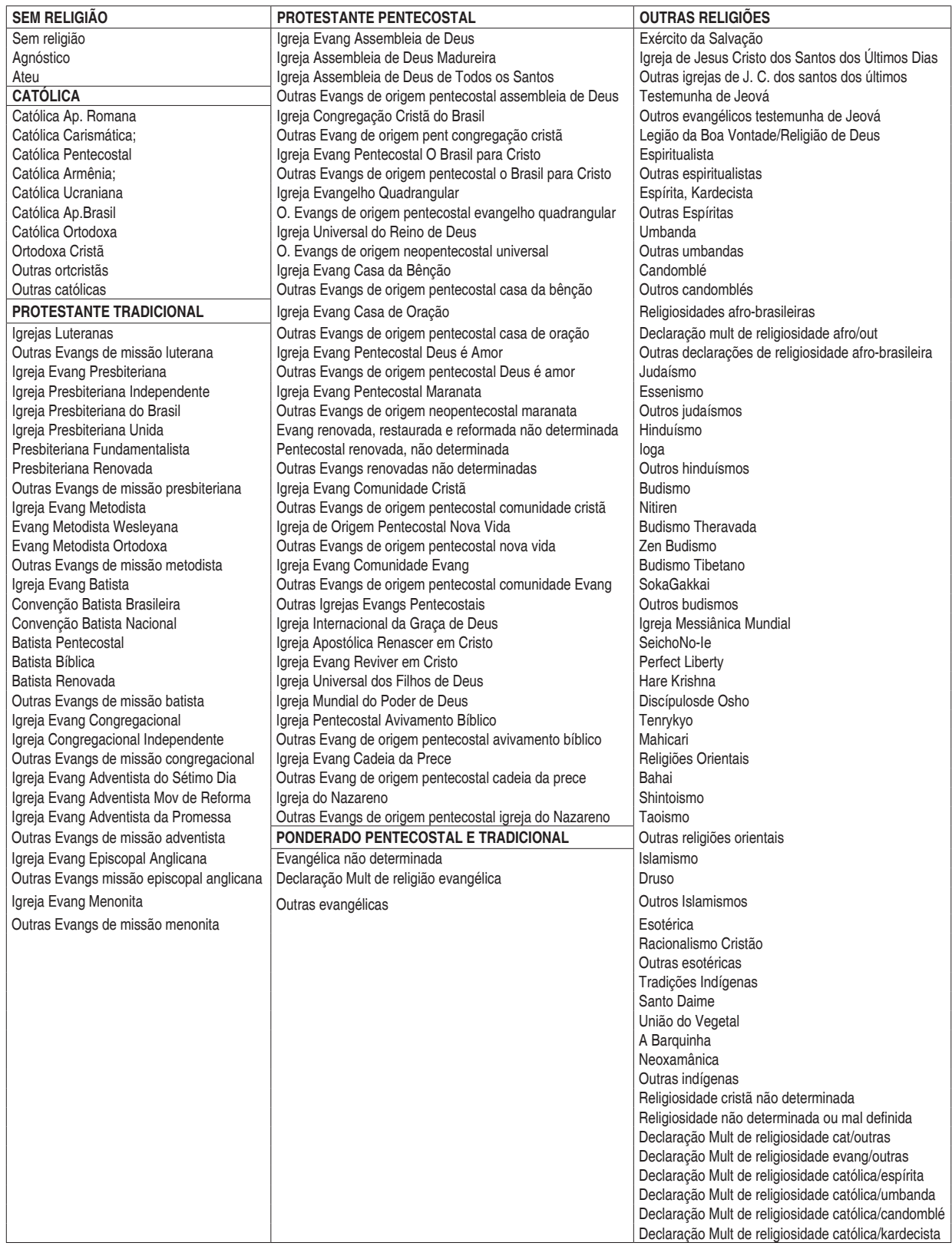

Fonte: Elaborado pelos autores a partir dos dados do IBGE (2018).

Notas: (i) V0310, v4090 e v6121 são os nomes das variáveis que representam Religião nos microdados dos censos de 1991, 2000 e 2010, respectivamente. (ii) Evang = Evangélica; Mult= Múltipla; Cat=Católica 
Anexo 2 - Relação linear entre as variáveis do estudo

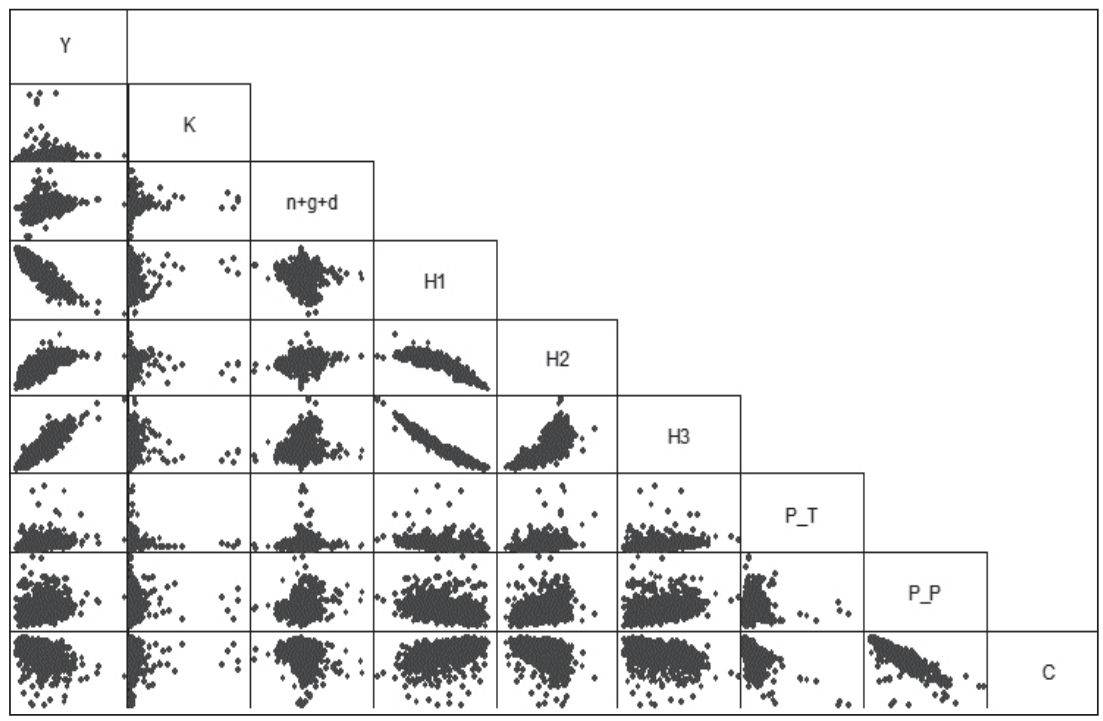

Fonte: Elaborado pelos autores a partir dos dados do IBGE e IPEA (2018).

Nota: a elaboração dessa figura ocorreu sem a logaritmização das variáveis.

Anexo 3 - Teste de fator de inflação da variância (FIV)

\begin{tabular}{llllll}
\hline VARIÁVEL & FIV & 1/FIV & VARIÁVEL & FIV & 1/FIV \\
\hline $\mathrm{K}$ & 1,45 & 0,691778 & $\mathrm{~K}$ & 1,42 & 0,706595 \\
$\mathrm{n}+\mathrm{g}+\delta$ & 1,2 & 0,83454 & $\mathrm{n}+\mathrm{g}+\delta$ & 1,21 & 0,828978 \\
$\mathrm{H} 2$ & 3,45 & 0,289457 & $\mathrm{H} 2$ & 3,37 & 0,296531 \\
$\mathrm{H} 3$ & 3,54 & 0,282335 & $\mathrm{H} 3$ & 3,47 & 0,287986 \\
$\mathrm{P}-\mathrm{T}$ & 1,28 & 0,779351 & P_P & 1,22 & 0,820591 \\
\hline
\end{tabular}

Fonte: Elaborado pelos autores (2018).

Anexo 4 - Valores mínimos das variáveis

\begin{tabular}{|c|c|c|c|}
\hline \multicolumn{4}{|c|}{ MÍNIMOS } \\
\hline & 1991 & 2000 & 2010 \\
\hline Renda & Lastro & Poço das Trincheiras & Santo Antônio do Içá \\
\hline Desp.Cap & Serra Preta & Careiro da Várzea & Careiro da Várzea \\
\hline $\mathrm{H} 1$ & Niterói & Niterói & Niterói \\
\hline $\mathrm{H} 2$ & Bom Jesus da Serra & Presidente Jânio Quadros & Melgaço \\
\hline $\mathrm{H} 3$ & Galinhos & Melgaço & Chaves \\
\hline P_P & diversos & diversos & Montauri \\
\hline P_T & diversos & diversos & diversos \\
\hline
\end{tabular}

Fonte: Elaborado pelos autores (2018). 
Anexo 5 - Valores máximos das variáveis

\begin{tabular}{cccc}
\hline & & MÁxIMOS & \\
\hline Renda & Águas de São Pedro & $\mathbf{2 0 0 0}$ & $\mathbf{2 0 1 0}$ \\
Desp.Cap & AMC de Pinhas e Piraquara & Águas de São Pedro & São Caetano do Sul \\
H1 & Gão Caetano do Sul & São Caetano do Sul \\
H2 & Óleo & Presidente Jânio Quadros & Melgaço \\
H3 & Niterói & Ipirá & Fernando de Noronha \\
P_P & Nova Brasilândia D'Oeste & Niterói & Niterói \\
P_T & Santa Maria de Jetibá & Tapauá & Alvinlândia \\
\hline
\end{tabular}

Fonte: Elaborado pelos autores (2018). 